\title{
Modelling public risk evaluation of natural hazards: a conceptual approach
}

\author{
Th. Plattner \\ Chair of Land Use Engineering, Swiss Federal Institute of Technology \\ Received: 22 September 2004 - Revised: 10 February 2005 - Accepted: 15 March 2005 - Published: 18 April 2005 \\ Part of Special Issue "Multidisciplinary approaches in natural hazard and risk assessment"
}

\begin{abstract}
In recent years, the dealing with natural hazards in Switzerland has shifted away from being hazard-oriented towards a risk-based approach. Decreasing societal acceptance of risk, accompanied by increasing marginal costs of protective measures and decreasing financial resources cause an optimization problem. Therefore, the new focus lies on the mitigation of the hazard's risk in accordance with economical, ecological and social considerations.

This modern proceeding requires an approach in which not only technological, engineering or scientific aspects of the definition of the hazard or the computation of the risk are considered, but also the public concerns about the acceptance of these risks. These aspects of a modern risk approach enable a comprehensive assessment of the (risk) situation and, thus, sound risk management decisions.

In Switzerland, however, the competent authorities suffer from a lack of decision criteria, as they don't know what risk level the public is willing to accept. Consequently, there exists a need for the authorities to know what the society thinks about risks. A formalized model that allows at least a crude simulation of the public risk evaluation could therefore be a useful tool to support effective and efficient risk mitigation measures.

This paper presents a conceptual approach of such an evaluation model using perception affecting factors $P A F$, evaluation criteria $E C$ and several factors without any immediate relation to the risk itself, but to the evaluating person. Finally, the decision about the acceptance $A c c$ of a certain risk $i$ is made by a comparison of the perceived risk $R_{i, p e r c}$ with the acceptable risk $R_{i, a c c}$.
\end{abstract}

1 Introduction: Dealing with natural hazards in Switzerland

Due to economical (increasing marginal costs of protective measures) and environmental reasons (negative ecological impacts of the protective measures) as well as societal concerns about hazardous events, dealing with natural hazards in Switzerland has recently shifted away from being hazardoriented towards a more risk-based approach. The protection against hazardous events is no longer the primary guideline for risk management, the new focus lies on the mitigation of the hazard risk in accordance with economical, ecological and social considerations. This newly introduced "culture of risk" is mainly characterized by PLANAT (the Swiss Natural Hazard Advisory Committee under the authority of the swiss government) and their paradigm: "From the avoidance of hazards towards a culture of risk" (PLANAT, 2005).

\section{State of the art: A risk-based approach or a new cul- ture of risk}

The modern swiss proceeding requires a comprehensive approach of dealing with hazard risks. Not only technological, engineering or scientific aspects of the definition of the hazard or the computation of the risk have to be considered, but also the public concerns about the acceptable level of these risks. Together, both aspects of a modern risk approach enable a comprehensive assessment of the (risk) situation and, thus, a sound decision about the necessary risk management measures. 


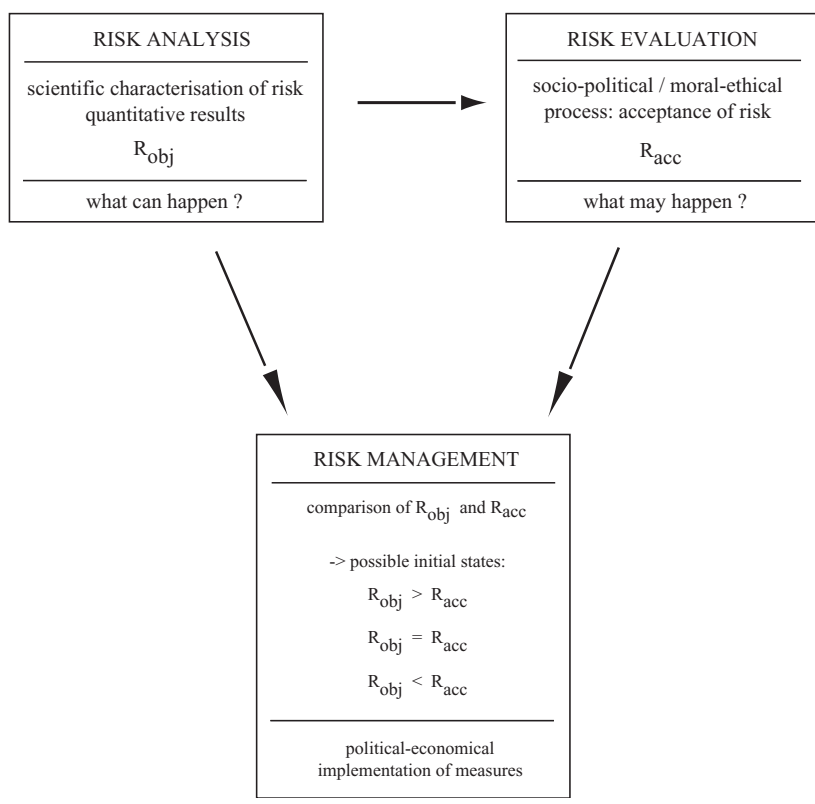

Fig. 1. The three cornerstones in a modern risk-oriented approach defining the "risk triangle": risk analysis, risk evaluation and risk management.

\subsection{The risk triangle}

It makes sense to base the swiss risk-based approach on the components risk analysis, risk evaluation and risk management as mentioned by Hollenstein (1997). These components are interrelated and influence each other what can be illustrated using the picture of 'risk triangle' (see Fig. 1).

Risk analysis is the process of quantification of the probabilities and expected consequences for identified risks and answers the question "What can happen?" (SRA, 2005). The resulting risk is often called the effective or objective risk $R_{o b j}$ and provides information about the extent and frequency of the expected damage of an event. The simplest definition of $R_{o b j}$ is the product of frequency (or probability) of event occurrence $F$ times the extent $E$ of the associated consequence, i.e.

$R_{o b j}=F \cdot E$

Risk evaluation is a socio-political and moral-ethical process in which judgements are made about the significance and acceptability of risks (SRA, 2005). It produces the information that is need to determine the acceptable level of residual risk $R_{a c c}$. Therefore, it answers the question: "What may happen?".

Based on possible initial states comparing the results of risk analysis and risk evaluation (see Fig. 1, risk management aims at reducing unacceptably high risks and preventing other risks from becoming so by maintaining a safe state. For this purpose, it combines $R_{o b j}$ and $R_{a c c}$ in a political process and implements measures based on economic and technological principles (Heinimann, 2002).

\subsection{Problems of a risk-based approach}

Despite the large potential of a risk-based approach for a sound and comprehensive dealing with natural hazards, there are problems that have to be addressed. Risk managers, who have to decide what level of risk is acceptable are mostly technological experts. But, very often they have to make judgements about the way the "lay" public perceives and evaluates the risks to account for societal concerns. As this information is usually not available, risk evaluation is often a knowledge gap in the risk management process.

A model that is able to simulate the public risk evaluation could be a helpful tool for the risk managers. Therefore, one of the aims of the proposed project carried out by the Chair of Land Use Engineering (LUE) of the Swiss Federal Institute of Technology in Zürich (ETH Zürich) is, primarily, the development of a conceptual framework of such a model and, secondarily, the testing and validation of these framework using case studies. Within this paper, however, the main focus lies on the conceptual framework.

Developing such an evaluation model, means addressing problems that can be summarized in the question: "What level of risk is acceptable $\left(R_{a c c}\right)$ and how can it be calculated in a model?". Although it is well documented what factors affect the perception of risks, it is still not absolutely clear which of these factors are relevant for the evaluation of natural hazards. Most of the perception research within the last thirty years was made in the field of technological hazards. The research is mainly based on the initial work of Farmer (1967) and Starr (1969) and was then improved by e.g. Slovic (e.g. Slovic et al., 1986; Slovic, 1987), Renn (e.g. Renn, 1998, 2001; Renn and Klinke, 2002) and others (e.g. Kasperson et al., 1988; Zwick et al., 2002). Nevertheless, during the last years, several research studies were also conducted in the field of natural hazard risk perception (e.g. Litai et al., 1983; Rogers, 1984; Fell, 1994; McDaniels et al., 1995, 1996; Finlay and Fell, 1997; DeChano and Butler, 2001; Plapp, 2004; Siegrist et al., 2004).

Furthermore, there exist several attempts to integrate risk perception findings in engineering approaches of risk evaluation. So far, in Switzerland such integrative work was essentially done in the field of technological hazards on behalf of companies or federal agencies (e.g. Schneider, 1985; Bohnenblust and Troxler, 1987). In recent years, also policy guidelines and regulatory applications of swiss federal agencies integrating these approaches were developed (e.g. BUWAL, 1999; EDI, 1989).

\subsection{Current approaches of risk evaluation in switzerland}

There is a small number of approaches to define an acceptable level or risk $R_{a c c}$ applied in Switzerland. On the level of the individual risks are these the approaches of the absolute Threshold Values of risk (Risiko-Grenzwerte) and the Marginal Costs (Grenzkosten) that the society is willing to pay to prevent damage, e.g. one casualty (e.g. Merz et al., 1995; Bohnenblust and Slovic, 1998; BABS, 2005). 
The evaluation of the collective risk and the definition of an acceptable level is sometimes done using the Boundary Line approach (e.g. Farmer, 1967; EDI, 1989). Due to its comprehensibility, it is mainly applied in regulatory applications. However, more important is the approach of the Aversion Term (e.g. Bohnenblust, 1985; Schneider, 1985; Bohnenblust and Troxler, 1987). This approach is used frequently in the field of natural hazards (e.g. BUWAL, 1999; BABS, 2005), although it was mainly developed in the field of technological hazards (e.g. Litai et al., 1983; Bohnenblust, 1985; Schneider, 1985).

Both formal procedures of collective risk evaluation are based on the same theoretical assumption: the difference between the effective risk $R_{o b j}$ and the acceptable risk level $R_{a c c}$ (Boundary Line) or the perceived risk $R_{\text {perc }}$ (Aversion Term) is caused by the extent $E$ of the direct damage of an event. The extent $E$ of the direct damage works as the basis for the risk aversion $\alpha$, according to

$\alpha=f(E)=\alpha(E)$

Thus, according to these two approaches, risk aversion $\alpha$ is the driving criteria of risk evaluation and is a surrogate for the public concerns about the (large) extent of event damage and the incalculable indirect costs following such an event. The indirect costs contain a number of aspects, e.g. the costs of recovery, costs of medical care and the costs of destroyed infrastructure (e.g. Schneider, 1985; Bohnenblust and Troxler, 1987; Merz et al., 1995; Fuster, 2004) that have to be defined seperately for every event.

\subsubsection{Boundary line}

The two procedures differ in the way of including risk aver$\operatorname{sion} \alpha$. Within the approach of the Boundary Line constant risk $R_{\text {const }}$ is represented on a double-logarithmic chart, plotting the frequency $F$ and the extent of damage $E$ of events, by a line with the gradient $g(B)$

$g(B)=\frac{\Delta(\log (F))}{\Delta(\log (E))}=-1$

and risk aversion can, therefore, be accounted for by changing the slope of the boundary line such that

$g(B) * \alpha=g^{*}(B)=\frac{\Delta\left(\log \left(F^{*}\right)\right)}{\Delta(\log (E))}<-1$

i.e., if the extent of damage doubles, the acceptable frequency of an event is no longer half as high, but less than half. In Switzerland, this approach is used e.g. in the Swiss Ordinance on Technological Hazards (EDI, 1989). However, a problem of this approach is that it is often not obvious if and to what extent risk aversion has been integrated.

\subsubsection{Aversion term}

The aversion term approach integrates the risk aversion in the representation of the actual risk, either using a factor $\alpha(E)$

$R_{A C}=F \cdot E \cdot \alpha(E)$ or an exponent

$R_{A C}=F \cdot E^{\alpha}$

The author calls the outcome of this approach "aversioncorrected" risk $R_{A C}$ due to the fact that only the extent of damage is considered using the aversion $\alpha$. In current practice, however, the resulting risk is often called "perceived risk" $R_{\text {perc }}$, although all the rest of the factors (e.g. mentioned in the proposed literature in Sect. 2.2) affecting the perception and the evaluation of risk are disregarded.

This approach is often combined with the marginal costs approach. The aversion-corrected $R_{A C}$ (or even perceived risk $\left.R_{\text {perc }}\right)$ is mostly multiplied with the marginal costs of a damage indicator (i.e. the costs that the society is willing to pay to prevent that damage). The resulting value is called the monetarised, aversion-corrected (or even "perceived") collective risk and enables the comparison of different risks and, thus, the definition of a acceptable risk level (e.g. Merz et al., 1995; BABS, 2005)

Both in the case of the Boundary Line and the Aversion Term, the relations

$\alpha(E)>1 \quad$ and $\quad d \alpha / d E>0$

hold, i.e. risks with a greater extent of damage are artificially and progressively increased.

\section{Principles of a conceptual approach of natural hazard risk evaluation}

The current risk evaluation approaches provide a wealth of knowledge for the development of a conceptual risk evaluation approach regarding natural hazards. But it has to be assumed that there are differences between the characteristics of technological and natural hazard risks that must be taken into account in an evaluation approach. Therefore, the proposed concept is based on the following elements:

- a mathematical formalization of the theoretical model background,

- a sound representation of the knowledge about risk perception and evaluation of natural hazard risks, and

- the appropriate role and representation of the evaluating person

\subsection{The theoretical background of the conceptual approach}

Using the proposed conceptual approach, three different types of risk are relevant (see Fig. 2). The personal estimation of the effective risk $r_{o b j}$ is the point of origin for the risk perception. But as stated in Sect. 2.2, there are several factors influencing the perception that are not included in the figure of the objective risk.

These factors are key elements for the calculation of the perceived risk $r_{\text {perc }}$ that either can be smaller or larger than 


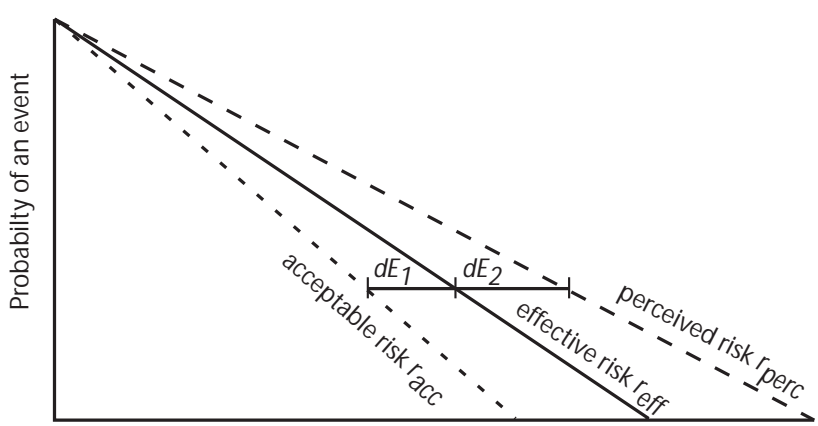

Extent of damage

Fig. 2. The three different types of risk used in the proposed conceptual approach and the differences $d E_{1}$ and $d E_{2}$ which are caused by the effects of the Perception Affecting Factors $P A F$ and Evaluation Criteria $E C$.

the ojective risk $r_{o b j}$. In Fig. 2 it is assumed that the perceived risk is larger than the effective risk, depending on the occurrence of the relevant perception affecting factors. The effective (or objective risk) and the perceived risk do not provide the necessary information about the acceptance of a certain risk. Therefore, the acceptable risk $r_{a c c}$ has to be known. In Fig. 2 it is assumed to be smaller than the perceived and the objective risk. The differences $d E_{1}$ (between $r_{a c c}$ and $r_{o b j}$ ) and $d E_{2}$ (between $r_{o b j}$ and $r_{p e r c}$ ) are caused by different occurrence of the relevant factors. In the proposed approach, these factors with their specific occurrence are called Perception Affecting Factors $P A F$ and Evaluation Criteria $E C$.

The conceptual approach is based on two "models". On the one hand a "risk model" aiming at modelling the risk, and on the other hand a "person model" aiming at modelling the evaluating person.

There are three relevant assumptions as a basis for the "risk model". Firstly, the perceived individual risk $r_{\text {perc }}$ does not comply with the objective individual risk $r_{o b j}$ (see also Fig. 2), i.e.

$r_{\text {perc }} \neq r_{\text {obj }}$

Secondly, it is assumed that, using a set of perception affecting factors $P A F$ as well as the objective individual risk $r_{o b j}$, the perceived individual risk $r_{p e r c}$ can be calculated according to

$r_{\text {perc }}=f\left(P A F, r_{o b j}\right)$

And thirtly, it is assumed that the acceptable individual risk $r_{a c c}$ can be calculated, in accordance with the opinion of Hollenstein (1997), using the evaluation criteria $E C$ and the perceived individual risk $r_{\text {perc }}$

$r_{a c c}=f\left(E C, r_{\text {perc }}\right)=f\left(E C, P A F, r_{o b j}\right)$

The general conceptual model approach is defined by the way the above mentioned model parameters are combined. It seems to be useful to choose a geometric approach with an amplification effect for e.g. the overal $P A F$ when several paf $_{i}$ change since the individual $P A F$ components have a multiplicative effect after

$r_{\text {perc }}=r_{o b j} *\left(\left(a_{1} * p a f_{1} * a_{2} * p a f_{2} * \ldots * a_{n} * p a f_{n}\right)\right)(11)$

where $a_{i}$ is the weight and $p a f_{i}$ the value of the $i$ th $P A F$ component. Thereby, the following relation holds

paf $_{i}=1 \Leftrightarrow$ neutral value of paf $_{i}$

For the acceptable risk $r_{a c c}$ the same combination rules are valid, so that it looks like

$r_{a c c}=r_{p e r c} *\left(\left(a_{1} * e c_{1} * a_{2} * e c_{2} * \ldots * a_{n} * e c_{n}\right)\right)$

where $a_{i}$ is the weight and $e c_{i}$ the value of the $i$ th $E C$ component. Thereby, the following relation holds, too

$e c_{i}=1 \Leftrightarrow$ neutral value of $e c_{i}$

The "person model", finally, is used to create model evaluators $m e_{i}$ with the help of a Monte-Carlo-Simulation. These model evaluators are supposed to be surrogates for the real life individuals and will then be provided with an appropriate weighting factor $g_{m e_{i}}$.

The "risk model" and the "person model" will be combined after

$r_{p e r c, m e_{i}}=r_{o b j} \cdot P A F \cdot g_{m e_{i}}$

for the perceived risk and in accordance with

$r_{a c c, m e_{i}}=r_{p e r c} \cdot E C \cdot g_{m e_{i}}$

for the acceptable risk. Consequently, the decision about the acceptance $A c c$ of a certain individual risk $r_{i}$ can now be made in accordance with Eq. (17)

$A c c=\left\{\begin{array}{l}1 \text { if } r_{\text {perc }, m e_{i}} \leq r_{a c c, m e_{i}} \\ 0 \text { if } r_{\text {perc }, m e_{i}}>r_{a c c, m e_{i}}\end{array}\right.$

As the proposed risk evaluation approach aims at modelling the evaluation of the collective risk $R$, this risk has to be calculated. In its easiest definition, the collective risk is defined as the sum of all individual risks $r$ of a community according to

$R=\sum_{i=1}^{n} r_{i}$

Therefore, it is possible to compute the perceived collective risk $R_{\text {perc }}$ as well as the acceptable collective risk $R_{a c c}$ in accordance with Eq. (18), so that the acceptance Acc of a certain collective risk can now be made after

$A c c=\left\{\begin{array}{l}1 \text { if } R_{\text {perc }} \leq R_{a c c} \\ 0 \text { if } R_{\text {perc }}>R_{a c c}\end{array}\right.$

If a certain collective risk $R_{i}$ is acceptable $(A c c=1)$, this risk $R_{a c c, i}$ can now be compared with the objective collective risk $R_{o b j, i}$ within the risk management. This comparison may provide three possible states, i.e.

$R_{o b j, i}<R_{a c c, i}$ 
$R_{o b j, i}=R_{a c c, i}$

$R_{o b j, i}>R_{a c c, i}$

The states of Eqs. (20) and (21) only require monitoring, whereas the state characterized by the Eq. (22) means that risk mitigating measures or measures increasing the acceptance of the risk have to be taken.

\section{A proposition for the implementation of the current knowledge about risk perception and evaluation}

One of the major objectives of this study is to advance the consideration of the current knowledge about risk perception and evaluation of natural hazards in the approaches of risk evaluation. Therefore, the use of perception affecting factors $P A F$ and evaluation criteria $E C$ is suggested to compute the perceived indidvidual risk $r_{\text {perc }}$ and the acceptable individual risk $r_{a c c}$.

\subsection{Perception Affecting Factors $P A F$ and Evaluation Cri-} teria $E C$

The $P A F$ are the relevant driving factors of natural hazard risk perception on the individual level. The determination of the $P A F$ is based on a survey of literature about risk perception in all fields of risks but a main focus of natural hazards (e.g Farmer, 1967; Starr, 1969; Slovic et al., 1986; Slovic, 1987; Fell, 1994; McDaniels et al., 1995, 1996; Finlay and Fell, 1997; Renn, 1998, 2001; Renn and Klinke, 2002; Zwick et al., 2002; Plapp, 2004)). Subsequently, a qualitative selection process aiming at the elimination of collinearity effects among the factors was conducted. The resulting set of factors was submitted to a group of experts from technological, administrative and social institutions dealing with natural hazards. These experts assessed the relevance of the individual factors for the perception of natural hazard risks and these results were then compiled. Consequently, a smaller list of relevant factors affecting the perception of risk resulted and was tested, again on a qualitative basis, a second time for collinearity, such that redundant factors could be grouped without significant loss of information (see Table 1).

The $P A F$ are used to calculate $d E_{2}$ after

$d E_{2}=f(P A F)$

and thus

$r_{\text {perc }}=r_{o b j}-d E_{2}$

The influence of a single $P A F$ on the perception of a risk can be illustrated with the example of the "voluntariness". As the literature shows, there is more willingness to accept voluntary than involuntary risks and involuntary risks are perceived to be higher than voluntary risks (e.g Starr, 1969). Based on these facts, it can be assumed that a risk that is taken voluntarily may be larger than the effective risk $r_{o b j}$, and, on the other hand, that an involuntarily taken risk should be smaller than the effective risk (see Fig. 3). Thus, it can be
Table 1. List of relevant perception affecting factors $P A F$, incorporating a subjective measure of the components of the effective risk $r_{o b j}$. The factors in the column on the right are those known from literature. Note: The suggested selection of factors is work in progress and subject to change.

\begin{tabular}{ll}
\hline$P$ erception Affecting $F$ actor & represents \\
\hline Voluntariness: & Voluntariness \\
Reducibility: & Reducibility, \\
& Predictability, \\
& Avoidability \\
Knowledge: & Familiarity, \\
& Knowledge about risk, \\
& Manageability \\
Cndangerment: & Controllability, \\
& Number of people affected, \\
& Fatality of consequences, \\
& Distribution of victims \\
& (spatio-temporal), \\
& Scope of area affected, \\
& Immediacy of effects, \\
& Directness of impact \\
Subjective measure of: & \\
\hline Extent of damage: & Extent of damage \\
Frequency of event: & Frequency of event \\
\hline
\end{tabular}

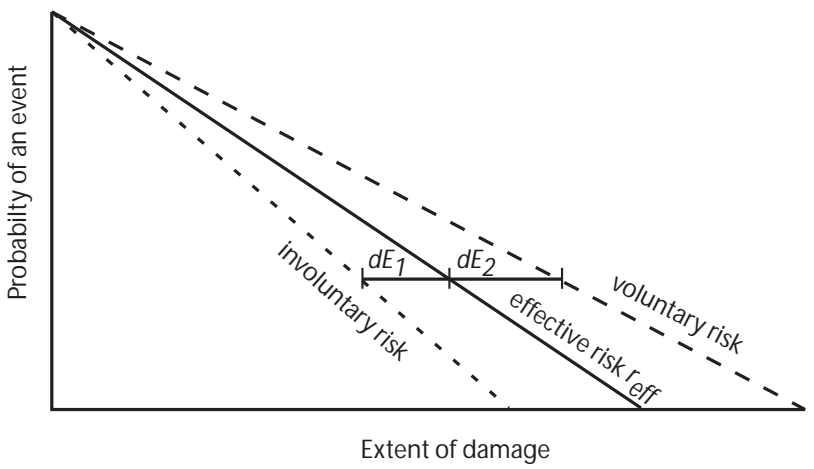

Fig. 3. The difference $d E_{1}$ and $d E_{2}$ between can, at least partly, be explained by additional factors, as e.g. the voluntariness of a risk.

drawn the conclusion, that the acceptable level of an involuntary risk should be lower than the acceptable level of a voluntary risk.

According to Hollenstein (1997) the evaluation of a risk is based on the perception of the risk. The key question is, what are the criteria to define the level of the acceptable risk, i.e. what are the relevant Evaluation Criteria $E C$ ? These criteria are important for the definition of the acceptable indivdual risk $r_{a c c}$.

As a working hypothesis, it is assumed that the in Table 1 mentioned factors can also be used as Evaluation Criteria $E C$ to calculate $d E_{1}$ after

$d E_{1}=f(E C)$ 
Table 2. The $P A F$ and $E C$ and their component values and weighting values. Note: the weighting value $w$ is the result of an expert workshop at the ETH Zürich on 23.11.2004.

\begin{tabular}{lll}
\hline$P A F / E C$ & $\begin{array}{l}\text { Component } \\
\text { value }\end{array}$ & $\begin{array}{l}\text { Weighting } \\
\text { value } w\end{array}$ \\
\hline$[0.5-2.0]$ & {$[0.0-1.0]$} \\
\hline $\begin{array}{l}\text { Voluntariness } \\
\text { Reducibility }\end{array}$ & $\mathrm{v}=[0.5-2.0]$ & $\mathrm{w}(\mathrm{v})=0.375$ \\
Knowledge & $\mathrm{r}=[0.5-2.0]$ & $\mathrm{w}(\mathrm{r})=0.333$ \\
Endangerment & $\mathrm{ex}=[0.5-2.0]$ & $\mathrm{w}(\mathrm{ex})=0.875$ \\
Measured & $\mathrm{d}=[0.5-2.0]$ & $\mathrm{w}(\mathrm{d})=0.667$ \\
extent of consequences $C_{\text {exp }}$ & $C_{\text {exp }}=[0.5-2.0]$ & $\mathrm{w}\left(C_{\text {exp }}\right)=1$ \\
Measured frequency $F$ & $F=[0.5-2.0]$ & $\mathrm{w}(F)=1$ \\
\hline
\end{tabular}

and thus

$r_{a c c}=r_{o b j}-d E_{1}$

Thus, a factor is not only relevant for the perception of a risk, but also for the evaluation of a risk after

$E C=f(P A F)$

and it can be assumed that the occurrence of a factor for the evaluation of risk is different from the occurrence of the same factor for the perception of risk. Additional Evaluation Criteria $E C$ according to

$c \in E C \wedge c \notin P A F$

will only be defined if it appears to be required for the model.

\subsection{Quantification of $P A F$ and $E C$}

The quantification of the $P A F$ and $E C$ is an important step. Several data sources are analysed with regard to quantitative values for the $P A F$ and the $E C$ :

- risk perception literature: explanation reports about risk perception studies (with a focus on studies accomplished in central Europe).

- data from a recently finished survey about the perception of natural hazards risks in Germany (Plapp, 2004).

- data from a survey about the perception and evaluation of natural hazard risks in Switzerland (Siegrist et al., 2004).

In accordance with the findings of risk perception and evaluation research, it has to be stated that risk aversion is more than a function of the extent of direct damage. For example, the indirect effects of hazardous events (e.g. costs of enacted laws, costs of psychological support of affected people, cost of recovery actions, etc.) have also to be considered. Both indirect and direct effects can e.g. be included in the term expected consequences $C_{\text {exp }}$.
The proposed model of natural hazard risk evaluation works, therefore, with an enhanced definition of risk aversion. In addition to the expected extent of damage $E$, more aspects are included that are assumed to be important. These are mainly the following items:

- Expected extent of consequences $C_{\exp }$ of an event.

- "Speciality" of an event (extraordinary event vs. normal events): the speciality of an event can be measured using a surrogate, e.g. the frequency (or the probability of occurrence) of the event.

- Perception Affecting Factors $P A F$ : since the magnitude of the potential damage is relevant for the risk evaluation, the scale for judging this magnitude is also important. The reluctance of an event $i$ may be stronger than that of an event $j$ even though the relations $R_{o b j, i}<R_{o b j, j}$ and $C_{\text {exp }, i}<C_{\text {exp }, j}$ may hold. This can e.g. occur when $i$ results from an involuntary and $j$ from a voluntary activity. The influence of the perception affecting factor 'Voluntariness' results in the relation $R_{\text {perc }, i}>R_{\text {perc }, j}$.

Thus, within the propsed conceptual approach both the expected consequences $C_{\text {exp }}$ and the frequency $F$ (or probability $p$ ) of an event have to be integrated within the $P A F$ and $E C$ (see Table 2).

The relevant factors of risk perception and evaluation have to be "transformed" into figures. When calculating a specific risk, the $P A F$ and $E C$ receive a component value between 0.5 and 2.0 (that is equal to $p a f_{i}$ after Eq. (11) and Eq. (12) or $e c_{i}$ after Eq. (13) and Eq. (14) and a specific weighting value (that is equal to $a_{i}$ within the Eq. (11) and Eq. (13)) that is currently based on an expert workshop hold at the ETH Zürich (see Table 2).

The extent of risk aversion can then be estimated e.g. using the values of the expected consequences $C_{\text {exp }}$ (or, as an approximation, the extent of the direct damage $E$ ), the frequency $F$ (or the probability of occurrence) of an event as well as the weighting of the factors affecting the perception $(P A F)$ and the evaluation $(E C)$ of a risk. Thus, the findings of Kahneman and Tversky (1979) have to be taken into account. The Prospect Theory reveals that human risk perception is an asymmetric and non-linear process in which more emphasis is put on the "losses" as a possible outcome of a decision than on the possible "gains" (see Fig. 4).

The value (utility) function of the Prospect Theory is based on the assumption that changes are the carriers of value and these changes are made in relation to a reference point working as the zero point of the value scale

$v(x)=0$

As shown in Fig. 4, the resulting value function is concave for gains and convex for losses and is steepest at the reference point itself. Furthermore, the value function for losses is steeper than the value function for gains and the marginal value for both gains and losses are decreasing. But 


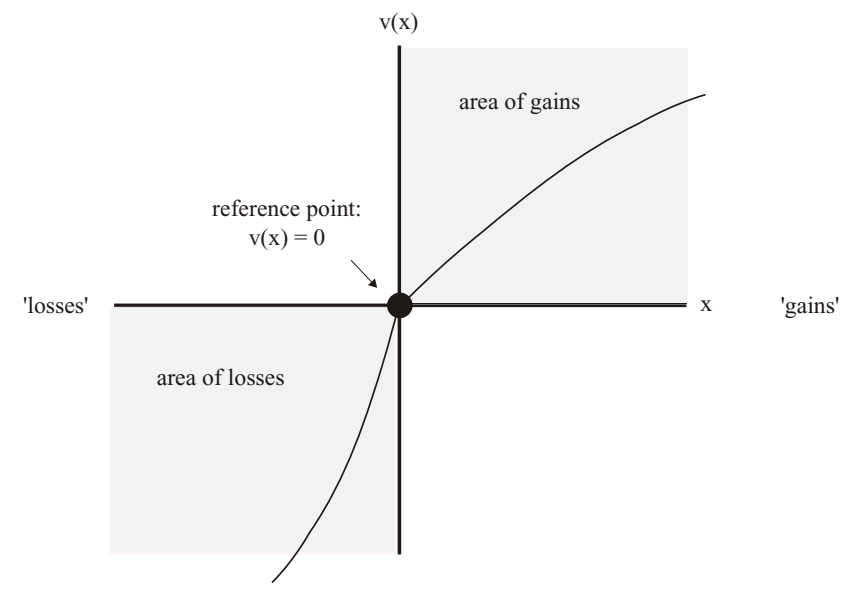

Fig. 4. The asymmetric and non-linear value function of the Prospect Theory (Kahneman and Tversky, 1979) puts more emphasis on "losses" than on "gains".

finally, the value function can also be convex for gains and concave for losses since, as Kahneman and Tversky (1979) write, the derived value function of an individual does not always reflect "pure" attitudes to money, since it could be affected by additional consequences associated with specific amounts. Such perturbations can readily produce convex regions in the value function for gains and concave regions in the value function for losses. The latter case may be more common since large losses often necessitate changes in life style.

Using the findings of the Prospect Theory, a possible concept for estimating the extent of risk aversion could be the measure of the aversive and non-aversive impacts of $P A F$ and $E C$. Such a measure can be done e.g. using a proceeding like the one drafted in Table 3. The component values $p a f_{i}$ and/or $e c_{i}[0.5-2.0]$ describe the occurrence of a $P A F$ and/or a $E C$ in a certain risk situation.

The super-proportional weighting of the "losses" complies with the assumption of risk aversion used in the introduced approach: an outcome that does not comply with the objectives and the idea of a "gain" of the relevant people, is weighted as a "loss" and, thus, defined as an negative outcome. For example, according to the perception affecting factors $P A F$, an involuntary activity causes risk aversion. Thus, involuntariness has to be accounted for as a "loss" (due to the fact that, according to the Prospect Theory, "losses" causes risk reluctance). This means that the term "loss" is a surrogate for involuntary, irreducible and dreadful risks and those with a high extent of consequences $C_{\text {exp }}$ and a high frequency. The term "gain", consequently, reflects opposite aspects: it is a surrogate for voluntary, reducible and dreadless risks with a small extent of consequences and a low frequency.
Table 3. The terms "Loss" and "Gain" of the Prospect Theory are used as surrogates for a specific set of the risk aversion characteristics. They get the value of 2 ("Loss"), 1 ("Neutral") and 0.5 ("Gain") and work as $p a f_{i}$ or $e c_{i}$ within the Eqs. (11) to (14).

\begin{tabular}{llll}
\hline Component & "Loss" & "Neutral" & "Gain" \\
\hline PAF: & Involuntary & Neutral & Voluntary \\
& Reducible & Neutral & Irreducible \\
& Experience with & Neutral & No experience with \\
& Dreadful & Neutral & Without dread \\
& Measure of large & & Measure of small \\
& extent of $C_{\text {exp }}$ & Neutral & extent of $C_{\text {exp }}$ \\
& Measure of high $F$ & Neutral & Meassure of low $F$ \\
Value: & 2 & 1 & 0.5 \\
Results in: & Risk aversion & Neutral & No risk aversion \\
\hline
\end{tabular}

\subsection{The representation of the evaluating person}

The proposed risk evaluation approach aims at modelling the evaluation of the collective risk $R_{\text {coll }}$. In its easiest definition, the collective risk can be defined as the sum of all individual risks $r_{\text {perc }}$ of a community according to Eq. (18).

The risk $r_{\text {perc }}$ perceived by an individual not only depends on the above mentioned $P A F$ factors and the effective risk $r_{o b j}$, but also on factors that have no immediate relation to the risk itself, but to the evaluating person. Among these factors are for example:

- the person's economic perspectives

- his or her social environment (structural and cultural properties of the community)

- his or her values and world views

- his or her psychological and behavioral characteristics (e.g. risk seeking vs. risk averse)

These individual factors should be accounted for in a comprehensive approach of risk evaluation, even though the model aims at the collective acceptable risk level $R_{a c c}$. However, considering these factors on a really individual basis is almost impossible, since it would in principle require that data about each and every person is gathered. Instead, a surrogate "model evaluator" is introduced. For this purpose, a broad classification for each of the above mentioned individual evaluation factors is defined (e.g., limited/average/good economic perspectives, instable or poorly developed/stable and well developed social environment, etc.). Subsequently, the frequency distribution of the population for all factors and classes is estimated (e.g. relying on national statistic data) together with the qualitative effect that a certain class assignment has on the perception. For example, limited economic perspectives or a poorly developed social environment may make all natural risks appear more (e.g., twice as) severe than good economic perspectives or a well developed social environment, since it is more difficult for the individual to recover from. Once the frequency distribution and the effects 
are determined, a Monte-Carlo simulation can be used to investigate and aggregate a large number of 'model evaluators' (each one having an 'individual' accepted risk $r_{i n d}$ ) and thus also the $R_{a c c}$ can be computed and the acceptability judgement according to Eq. (19) can be made. This is current work in progress.

\section{Discussion: The difficulties of the proposed approach}

Developing a model requires decisions about the relevance of several parameters affecting the modelled process. On one hand, the more parameters are considered, the better does the model correspond to reality, but the more demanding it is to use this model. On the other hand, if fewer parameters are used, then the application of the model is easier and the results are generally more stable. However, this comes at the cost of an increased probability of having omitted relevant factors. The model building process is thus a trade-off between the applicability and the representativeness of the model.

From a risk management point of view, a model that allows at least a rough, though still not completely accurate estimation of the risk evaluation is better than having nothing at all. In engineering terms, this means that the goal is a simple and sound model rather than a sophisticated and complicated one. Therefore, the emphasis is on a small number of relevant factors affecting the risk evaluation, allowing for a certain inaccuracy of the model results.

However, several critical points of the proposed model must be remain. First, the idea to derive a normative formulation from social and psychological factors originally derived in a non-normative context and applying this formulation within an engineering context may give raise to questions. However, managing risks involves making decisions, and while it is obvious that a perfect representation of the real risk evaluation will never be possible, one should nevertheless try to improve the basis for the decision making. The goal is not to replace the evaluation process, but to facilitate the selection of 'good' options (i.e., those that are likely to be in line with the evaluation) within the framework of risk management.

A second issue is the definition of the $P A F$ components as suggested above (including their weights and scales). It is obvious that lay persons play a vital role in evaluating risks. They should be represented in the definition of the factors that drive the model. This was not possible due to time and budget constraints. This is a shortcoming of the chosen approach, but the author hopes that he will be able to (partly) compensate it by using the results of recent and current investigations about the public perception of natural risks from Switzerland and Germany for calibration and validation of the model.

A third issue is the inclusion of risk aversion in the evaluation process. While aversion was the only factor considered so far in formal evaluation procedures, it may almost disappear as a factor in the new model since it is expressed by the characteristics of the model parameters. Risk aversion is, compared to the current practice, used in a clearly different way and also with a different intention. One might argue that this should at least be reflected by using another terminology. However, it is the opinion of the author that the use of aversion is justified by the very meaning of the word. This would be a clear change in practice, and it remains to be seen if such a change will be endorsed by the risk management community.

A fourth issue is the use of "model evaluators" for representing individuals (and on an aggregate level also communities). Social classification has a tradition in psychology and sociology, but it has probably not been operationally used in a context similar to the present one. Currently, neither the sensible choice of the ideas nor the legitimacy of the assumption that they can be aggregated to represent communities is clear. Additional work will be necessary to provide a more solid foundation for the inclusion of perception factors that are not related to the risk characteristics.

A final issue for discussion is certainly the accuracy of the model predictions that can be achieved and the benefits that can be derived

from these predictions. Both factors will be difficult to estimate before the model can actually be applied to decisionmaking situations. Even if the model application is easy (i.e., not requiring a lot of effort for understanding or data procurement), it is still an additional step in the decision procedure with an initially unproven return. Thus, the benefits that improved information about risk evaluation provides in the risk management process must be actively communicated at least until the usage of the model is established in the risk management community.

\section{Conclusions}

A new culture of dealing with natural hazards requires a riskbased approach. But why is it necessary to introduce a new risk culture? What are the driving factors of this development?

In recent years, there is an increasing societal claim for security and a decreasing level of risk acceptance. Furthermore, there are increasing marginal costs of risk protective measures, but decreasing financial resources for the management of natural hazards. This results in an optimization problem and raises the questions "How can the financial resources be used most efficiently?" and "How can the most effective risk mitigation measures be achieved?". Since financial resources are becoming more and more restricted, the allocation of the money is regarded critically by the public. Therefore, the competent authorities, working on behalf of the society, have to consider not only the scientific findings and methods for computing the risk, but must also include the public concerns.

One of the key problems is the lack of information about what the societal risk acceptance ex-ante (i.e., before an event). After an event, the society often simply requires that a 
similar event may never happen again. There are many cases of catastrophic events, mainly in the field of technological hazards, that resulted in societal risk acceptance levels. An example is the fire in a chemical storage facility in Schweizerhalle in 1986 that led to the development of the Swiss Ordinance on Technological Hazards (Störfallverordnung) (EDI, 1989) that now regulates the handling of technological risks in Switzerland and considers the acceptable level of risk (using the approach of Boundary Line). However, examples of a proactive definition of a societal safety level are rare. In the field of natural hazards, the society never defined what levels of risk are acceptable. Thus, the competent authorities suffer from a lack of decision criteria, although the protection of the public is one of their major tasks. Consequently, there exists a need for the authorities to know what the society thinks about risks and what level of risk the society is willing to accept. A formalized model that allows the simulation of the public risk evaluation could be a useful tool to support effective and efficient risk mitigation measures.

Acknowledgements. This project is mainly realized on behalf of and financed by PLANAT, the Swiss Natural Hazard Advisory Comittee, and by the Swiss Federal Agency for Environment, Forest and Landscape (BUWAL), the Swiss Federal Agency for Waters and Geology (BWG) and the Swiss Federal Agency for Civil Defense (BABS).

Edited by: T. Glade

Reviewed by: two referees

\section{References}

BABS: Katastrophen und Notlagen in der Schweiz (KATARISK). Eine Risikobeurteilung aus der Sicht des Bevölkerungsschutzes, Bundesamt für Bevölkerungsschutz (BABS), http://www.babs. admin.ch, Access Date: 25.1.05, 2005.

Bohnenblust, H.: Die Anwendung eines risikoorientierten Sicherheitsmodells zur Beurteilung der Neubaustrecken der Deutschen Bahn, in: Risikountersuchungen als Entscheidungsinstrument Risk analysis as a decision tool, edited by: Yadigaroglu, Y. and Chakraborty, S., 1, pp. 341-361, Verlag TÜV Rheinland, Köln, 1985.

Bohnenblust, H. and Slovic, P.: Integrating technical analysis and public values in risk-based decision making, Reliability Engineering and System Safety, pp. 151-159, 1998.

Bohnenblust, H. and Troxler, C.: Risk analysis - Is it a useful tool for the politician in making decisions on avalanche safety?, in: Davos Symposium: Avalanche formation, movement and effects, edited by: Salm, B. and Gubler, H., 162, pp. 653-664, International Association of Hydrological Sciences (IAHS), Davos, 1987.

BUWAL: Kosten-Wirksamkeit von Lawinenschutz-Massnahmen an Verkehrsachsen, Vollzug Umwelt, Bundesamt für Umwelt, Wald und Landschaft (BUWAL), Bern, 1999.

DeChano, L. M. and Butler, D. R.: Analysis of public perception of debris flow hazard, Disaster Prevention and Management, 10, 261-269, 2001.

EDI: Verordnung über den Schutz vor Störfällen (Störfallverordnung, SFV), Entwurf, Eidgenössisches Departement des Innern (EDI), Bern, 1989.
Farmer, F.: Siting criteria - a new approach, in Containment and siting of nuclear power plants, edited by IAEA, pp. 303-329, International Atomic Energy Agency (IAEA), Wien, 1967.

Fell, R.: Landslide risk assessment and acceptable risk, Canadian Geotechnical Journal, 31, 261-272, 1994.

Finlay, P. and Fell, R.: Landslides: risk perception and acceptance, Canadian Geotechnical Journal, 34, 169-188, 1997.

Fuster, T.: Die Ökonomie von Naturgefahren. Orientierungsmarken der Asiatischen Entwicklungsbank, Neue Zürcher Zeitung (NZZ), Nr. 305, 30. Dezember, p. 21, 2004.

Heinimann, H.: Risk Management - a framework to improve effectiveness and efficiency of resource management decisions, in: 23rd session of the European Forestry Commission's working party on the management of mountain watersheds, edited by: Greminger, P., pp. 16-19, Bundesamt für Wald, Umwelt und Landschaft (BUWAL), Davos, 2002.

Hollenstein, K.: Analyse, Bewertung und Management von Naturrisiken, vdf, Hochschulverlag ETH Zürich, Zürich, 1997.

Kahneman, D. and Tversky, A.: Prospect Theory: an analysis of decision under risk, Econometrica, 47, 263-291, 1979.

Kasperson, R. E., Renn, O., Slovic, P., Brown, H. S., Emel, J., Goble, R., Kasperson, J. X., and Ratick, S.: The social amplification of risk: a conceptual framework, Risk Analysis, 8, 177-187, 1988.

Litai, D., Lanning, D., and Rasmussen, N.: The public perception of risk, in: The analysis of actual versus perceived risks, edited by: Covello, V., Flamm, W. G., Rodricks, J., and Tardiff, R. G., Advances in Risk Analysis, pp. 212-224, Plenum Press, New York/London, 1983.

McDaniels, T., Axelrod, L., and Slovic, P.: Characterizing perception of ecological risk, Risk Analysis, 15, 575-588, 1995.

McDaniels, T., Axelrod, L., and Slovic, P.: Perceived ecological risks of global change. A psychometric comparison of causes and consequences, Global Environmental Change, 6, 159-171, 1996.

Merz, H. A., Schneider, T., and Bohnenblust, H.: Bewertung von technischen Risiken, Beiträge zur Strukturierung und zum Stand der Kenntnisse, Modelle zur Bewertung von Todesfallrisiken., 1, vdf Verlag der Fachvereine, Zürich, 1995.

PLANAT: Naturgefahren: So wehrlos sind wir nicht, http://www. planat.ch/, Access Date: 25.1.05, 2005.

Plapp, T.: Perception and evaluation of risk from natural disasters, Phd Thesis, Universität Karlsuhe, 2004.

Renn, O.: The role of risk perception for risk management, Reliability Engineering and System Safety, 59, pp. 49-62, 1998.

Renn, O.: The need for integration; risk policies require the input from experts, stakeholders and the public at large, Reliability Engineering \& System Safety, 72, 131-135, 2001.

Renn, O. and Klinke, A.: A New Approach to Risk Evaluation and Management: Risk-Based, Precaution-Based, and DiscourseBased Strategies, Risk Analysis, 22, 1071-1093, 2002.

Rogers, G.: Public recognition of hazard, in: Uncertainty in risk assessment, risk management and decision making, edited by: Covello, V., Lave, L., Moghissi, A., and Uppuluri, V., 4 of Advances in risk analysis, pp. 103-116, Plenum Press, New York/London, 1984.

Schneider, T.: Ein quantitatives Entscheidungsmodell für Sicherheitsprobleme im nicht-nuklearen Bereich, in Risikountersuchungen als Entscheidungsinstrument - Risk analysis as a decision tool, edited by: Yadigaroglu, Y. and Chakraborty, S., 1, pp. 113-143, Verlag TÜV Rheinland, Köln, 1985.

Siegrist, M., Gutscher, H., Orlow, P., and Yoker, U.: Hochwassergefahren in der Schweiz: Risikobewusstsein in der Bevölkerung 
und die Implikationen für eine erfolgreiche Risikokommunikation. Schlussbericht, Tech. rep., Universität Zürich, Sozialforschungsstelle, 2004.

Slovic, P.: Perception of risk, Science, New series, 236, 280-285, 1987.

Slovic, P., Fischhoff, B., and Lichtenstein, S.: The psychometric study of risk perception, in: Risk evaluation and management, edited by: Covello, V., Menkes, J., and Mumpower, J., Contemporary issues in risk analysis, pp. 3-24, Plenum Press, New York, 1986.
SRA: Glossary of Risk Analysis, http://sra.org/resources_glossary. php, Access Date: 25.1.05, 2005.

Starr, C.: Social benefit versus technological risk, Science, New series, 165, 1232-1238, 1969.

Zwick, M., Renn, O., and Klinke, A.: Wahrnehmung und Bewertung von Risiken. Ergebnisse des "Risikosurvey BadenWürtemberg 2001”, Tech. Rep. 202, Akademie für Technikfolgenabschätzung, Lehrstuhl für Technik- und Umweltsoziologie der Universität Stuttgart, 2002. 